\title{
Práticas sexuais entre homens em tempos de mídias digitais: perspectivas e desafios ao campo da saúde
}

\author{
Men's sexual practices in the digital media age: perspectives and \\ challenges in the health field
}

\author{
Prácticas sexuales entre hombres en tiempos de la era digital: \\ perspectivas y desafíos en el campo de la salud
}

\begin{abstract}
Miskolci R. Desejos digitais: uma análise sociológica da busca por parceiros online. Belo Horizonte: Autêntica; 2017. 304 p. ISBN 97885-5130-259-0.
\end{abstract}

doi: 10.1590/0102-311X00020119

O livro do sociólogo Richard Miskolci 1 apresenta sua investigação sobre homens que buscam outros homens para encontros sexuais por meio de mídias digitais. A partir da sociologia digital, com ênfase nos estudos sobre gênero e sexualidade, o autor mostra os resultados de uma etnografia multissituada (São Paulo, Brasil e São Francisco, nos Estados Unidos), percorrendo caminhos on-line e off-line.

Miskolci descreve como a heterossexualidade é extremamente desejada por homens de classe média e classe média alta que buscaram, nos aplicativos, uma forma de vivenciar seu desejo com "discrição". Ser "discreto", "macho", "brother" e "fora do meio" representa um valor importante para eles, já que levavam uma vida social "hétero", mas, "em segredo”, mantinham relações sexuais com outros homens. Ser um "homem de verdade" implicaria uma performance pública heterossexual, viril e máscula, cumprindo os mandatos de masculinidade hegemônica 2 , ao passo que ser um homem declaradamente gay indicaria um status social inferior. O "segredo" reúne a capacidade de experimentar o desejo por outros homens e, ao mesmo tempo, não perder suas credenciais sociais masculinas. Ser publicamente heterossexual é uma espécie de imperativo, e enfrentar esse regime regulatório da visibilidade dos desejos e afetos pode ter custos sociais altos.

Pelo seu caráter de escolha e incitação a uma estética midiática, as mídias digitais tendem a transformar a busca amorosa em sexual, lançando os usuários numa teia de negociações de capitais diversos (corporal, cultural, simbólico), que antecede o sexo entre os interlocutores dos aplicativos, tais como: "Você tem local? É ativo ou passivo? É assumido ou na encolha?”.

Diante desse cenário, elencamos alguns questionamentos frente ao uso de mídias digitais para fins sexuais relevantes para o campo da saúde no contexto brasileiro. O primeiro se refere ao fenômeno "sexting", ou seja, a divulgação sem consentimento de mensagens e fotos eróticas por meio de celulares, que criou um pânico sexual sobre a circulação de imagens pornográficas ilegais, especialmente entre jovens e adolescentes. Estudos 3,4 apontam a necessidade do olhar atento dos profissionais de saúde para a problematização e a abordagem dessa violência digital junto a adolescentes e jovens.

Embora recente, a violência nas mídias digitais vem despertando interesse no campo da saúde e educação. Contudo, no que se refere às relações amorosas juvenis, particularmente entre gays, a produção de conhecimento é escassa, indicando a necessidade de estudos que busquem 
compreender como as dinâmicas de gênero são reproduzidas ou subvertidas nessas formas de violência digital.

O segundo se refere ao sofrimento psíquico nessa interação mediada pela Internet. Miskolci aponta que o parceiro ideal seria aquele "macho e fora do meio", jovem, branco, malhado, classe média, cabelo curto, com bigode, e que a recusa da "paquera on-line" é vivida solitariamente, ou seja, somente o usuário sabe que foi recusado. Como são as experiências daqueles que não se enquadram no perfil "macho e discreto"? Como homens mais velhos, negros, de diferentes classes e com corpos "fora do padrão" compreendem, vivenciam e negociam esses "códigos on-line"? Como eles experimentam e internalizam as "bloqueadas" em suas paqueras on-line?

Pesquisas internacionais 5,6,7 sugerem que as experiências de recusa geram sofrimento psíquico, baixa autoestima e ansiedade. No Brasil, estudos 8,9 discutem como diferentes formas de discriminação afetam a saúde mental. No entanto, há pouca produção científica que busque compreender como a discriminação, o racismo, a gordofobia e a rejeição do feminino afetam a produção de subjetividade de homens gays usuários de mídias digitais.

Por último, o autor destaca que as mídias digitais ampliaram a cena sexual, criando "armários digitais” 10, facilitando relações entre homens que não frequentavam espaços de sociabilidade gay.

Estudos 11,12 apontam um aumento do número de casos de infecção por HIV na população jovem masculina gay de 18 a 28 anos de idade e aumento de $200 \%$ em casos de sífilis, especialmente entre a população masculina gay $(56,6 \%)$. Contudo, essas pesquisas não citam o uso de mídias digitais como uma forma de socialidade que pode engendrar vulnerabilidades como o sexo desprotegido ou consumo de drogas. Como o campo da saúde tem percebido esse fenômeno frente à prevenção da aids e de outras IST, ao uso de drogas lícitas e ilícitas e à perpetração de violências nesses espaços? Ao mesmo tempo, é importante não recair em análises situadas no campo das moralidades 13, mas compreender que o uso de mídias digitais constitui um eixo central na socialidade contemporânea, sendo uma importante ferramenta para a produção de intervenções.
Por fim, somos mais de cinco bilhões de pessoas conectadas por telefone em diversas mídias sociais, representando $68 \%$ da população global. O Brasil é o terceiro país que mais fica on-line: mais de nove horas por dia ${ }^{14}$. Segundo a mesma fonte, nos últimos 25 anos, houve um aumento de $70 \%$ nas taxas de ansiedade e depressão, principalmente entre adolescentes e jovens, em que as mídias digitais tem um importante papel na construção de autoimagem e autoestima. Contudo, esse estudo não apresenta o perfil do jovem que faz uso das mídias digitais e não leva em conta sua orientação sexual ou classe social, dentre outras categorias de pertencimento.

Nessa direção, podemos questionar como os aplicativos para encontros sexuais estão afetando a saúde de homens gays, principalmente dos mais jovens? Como essa nova socialidade reflete e afeta a cultura gay? Que contribuições os estudos sobre mídias digitais podem trazer para o conhecimento da sexualidade masculina gay?

É importante produzir reflexões críticas sobre como essa socialidade digital vem criando novas formas de socialização, códigos próprios e engendrando vulnerabilidades entre seus usuários. Destaca-se, ainda, a permanência do imperativo da masculinidade hegemônica nos aplicativos de busca on-line por parceiros entre homens. Não basta um "corpo viril”, mas a necessidade da demonstração social da heterocisnormatividade aliada à classe social e à cor da pele.

Olhar para a Internet e suas plataformas de socialização voltadas ao público gay torna-se imperativo para a compreensão da produção de subjetividades e dos mecanismos de exclusões, hierarquizações, vulnerabilidades e violências que moldam as buscas desejantes on-line, articulando dimensões de iniquidade social e relações de poder.

\author{
Wendell Ferrari 1 \\ Marcos Nascimento 1 \\ 1 Instituto Nacional de Saúde da Mulher, da Criança e do \\ Adolescente Fernandes Figueira, Fundação Oswaldo Cruz, \\ Rio de Janeiro, Brasil. \\ wendellferraripsi@gmail.com
}




\section{Colaboradores}

W. Ferrari e M. Nascimento colaboraram na concepção, elaboração, redação e revisão da resenha.

\section{Informações adicionais}

ORCID: Wendell Ferrari (0000-0002-4597-5309); Marcos Nascimento (0000-0002-3363-4232).
1. Miskolci R. Desejos digitais: uma análise sociológica da busca por parceiros on-line. Belo Horizonte: Autêntica; 2017.

2. Connell RW. Masculinities. Berkeley: University of California Press; 1995.

3. Barros SC, Ribeiro PRC, Quadrado RP. Sexting: entendendo sua condição de emergência. EXEDRA Revista Científica ESEC 2014; Suppl:192-213.

4. Flach RMD, Deslandes SF. Abuso digital nos relacionamentos afetivo-sexuais: uma análise bibliográfica. Cad Saúde Pública 2017; 33:e00138516.

5. Beymer MR, Rossi, AD, Shu SB. Assessing selfcontrol and geosocial networking app behavior among an online sample of men who have sex with men. J Urban Health 2016; 93:698-708.

6. Lyons A, Heywood W, Fileborn B, Minichiello V, Barrett C, Brown G, et al. The sex, age, and me study: recruitment and sampling for a large mixed-methods study of sexual health and relationships in an older Australian population. Cult Health Sex 2017; 19:1038-52.

7. Goedel WC, Krebs P, Greene RE, Duncan DT. Associations between perceived weight status, body dissatisfaction, and self-objectification on sexual sensation seeking and sexual risk behaviors among men who have sex with men using Grindr. Behav Med 2017; 43:142-50.

8. Albuquerque GA, Garcia CL, Alves MJH, Queiroz CMHT, Adami F. Homossexualidade e o direito à saúde: um desafio para as políticas públicas de saúde no Brasil. Saúde Debate 2013; 37:516-24.
9. Bastos JL, Barros AJD, Celeste RK, Paradies Y, Faerstein E. Age, class and race discrimination: their interactions and associations with mental health among Brazilian university students. Cad Saúde Pública 2014; 30:175-86.

10. Vieira MDC. Vigilância e anonimato em aplicativos mobile: um estudo sobre a privacidade em relações homoafetivas no digital. Liinc em Revista 2016; 12:308-21.

11. United Nations Office on Drugs and Crime. World Drug Report 2013. New York: United Nations; 2013.

12. Programa Conjunto das Nações Unidas sobre HIV/AIDS. Prevention Gap report. Relatório global do UNAIDS sobre prevenção destaca avanços e desafios da resposta à AIDS no Brasil, 2015. https://unaids.org.br/2016/07/3883/ (acessado em 15/Dez/2017).

13. Mora C, Brigeiro M, Monteiro S. A testagem do HIV entre "HSH": tecnologias de prevenção, moralidade sexual e autovigilância sorológica. Physis (Rio J.) 2018; 28:e280204.

14. We Are Social. Digital in 2018: World's internet users pass the 4 billion mark. https:// wearesocial.com/blog/2018/01/global-digitalreport-2018 (acessado em 15/Dez/2017).
Recebido em 01/Fev/2019

Versão final reapresentada em 07/Fev/2019

Aprovado em 12/Fev/2019 